\title{
Intermodal stimulation as a motivator for choice behavior
}

DOUGLAS W. MATHESON

CLAREMONT GRADUATE SCHOOL

Eighteen animals run in a T-maze preferred light plus noise to light alone. The results were interpreted as supporting the Dember-Earl the ory.

It is interesting that few studies in the past 10 years have attempted to study the combined effects of both audio and visual stimulation on choice behavior. Symons (1963) mentioned that as early as 1669 , a Copenhagen anatomist reported that partially deaf people could hear better in the light than in the dark. Dember $(1961$, p. 221) reported that auditory stimulation increases sensitivity to blue-green light in humans, but that it lowers sensitivity to orange-red. He also stated that if the sound is composed of "harmonious tones," sensitivity to green and blue is lowered and sensitivity to red and yellow is increased; if on the other hand the sound is "disagreeable" (such as "white noise"), the opposite effect is noted.

Several studies have noted the motivating or reinforcing effects of either audio or visual stimulation alone on behavior. A rat study by Sackett (1963) found that changes in light stimulation was a motivator for bar pressing behavior. Butler (1958) found that "white noise" was a reinforcer for bar pressing behavior in rhesus monkeys. In a T-maze study, Levin \& Forgays (1960) reported that light change operated as a reinforcer for learning.

Dember \& Earl (1957) have maintained that stimuli with a certain degree of novelty will be approached. They have proposed a behavioral model for predicting and interpreting responses to changes in stimulation. It appears that intermodal stimulation, if novel and complex enough, could serve as a motivator for behavior.

The purpose of the present study was to investigate the effects of white noise (N) and/or two colored lights (Red-R and Green-G) on choice behavior of rats in a T-maze. The following experimental hypothesis was advanced: rats will prefer light plus white noise to light alone in a free choice T-maze situation.

Subjects

Eighteen naive Long Evans hooded rats (10 male and 8 female) approximately 6 months old were used. All animals were tamed by handling for $20 \mathrm{~min}$. a day for five days and were adapted to the apparatus for 5 min. a day for five days without the experimental stimuli present. All animals were fed and watered ad lib in their home cages.

\section{Apparatus}

A standard gray $\mathrm{T}$-maze constructed out of $3 / 4 \mathrm{in}$. plywood with a hardwear cloth top was used. The maze was equipped with three guillotine doors, one at the start box, and the other two were placed at the entrance to both goal arms. A 2 in. permanent magnet speaker was attached to the outside wall (away from the start box) approximately 1 in. from the end of each goal arm. A 28 volt, .17 watt light bulb was attached to the end of each goal arm so that a colored jeweled lens could be screwed over the bulb. The speakers were connected to a white noise generator (Lehigh Valley Electronics Model No. 1524) and regulated through a toggle switch. It appeared that there was adequate localization of the noise from either goal arm. The maze was placed into a large homogeneous gray plywood box (34 in. x 34 in. $x 56$ in.) open at the front and illuminated by four General Electric Lumiline Lamps. The box provided homogeneous extra maze stimulation and uniform lighting throughout the maze.

\section{Procedure}

The 18 animals were randomly assigned to six groups (three Ss per group). The groups were then assigned randomly to six conditions (treatments) of stimulation.

Each day, a given $S$ was individually placed into the apparatus without the experimental stimuli. Then the animal was given enough trials until it alternated arms once on successive trials. This procedure was to insure a relatively equal preference for either arm. A trial was defined as the placement of the $S$ into the start box at which time the door was opened to allow the animal to proceed down the starting alley and enter one of the goal arms. Upon entrance into one of the arms, the arm door was closed and the animal was removed as soon as possible to keep the experimental stimuli as novel as possible. The intertrial interval was approximately $5 \mathrm{~min}$.

The conditions of stimulation were as follows: Group I (RR/RG) received the pre-trial condition of five trials per day for two days with red lights (RR) in both goal arms. These trials were followed by five trials per day for six days with a red light in one arm and a green light in the other (RG). The position of the red and green was randomly assigned for all trials and Ss. Group II (GG/RG) received green in both arms (GG) for five trials per day for two days, followed by five trials per day for six days with the (RG) condition. Group III (RR/R-GN) received (RR) for five trials per day for two days followed by five trials per day for six days with (R) in one arm and green plus white noise (GN) in the other. Noise was always presented in the arm containing the green light and was turned on when the start door opened. The intensity of the noise was ad- 
Table 1. Duncan's New Multiple Range Test Applied to the Differences Between $k=6$ Treatment Means

Group Means ranked in order of magnitude

\begin{tabular}{cccccc} 
(V) & $(I I)$ & $(I)$ & $(I I)$ & $(V I)$ & $(I V)$ \\
$(-/ R G)$ & $(G G / R G)$ & $(R R / R G)$ & $(R R / R-G N)$ & $(-/ R-G N)$ & $(G G / R-G N)$ \\
14.33 & 15.00 & 15.00 & 19.33 & 20.00 & 20.33 \\
\hline
\end{tabular}

Any two treatment means not underscored by the same line are significantly different $(p<.01)$

Any two treatment means underscored by the same line are not sig nificantly different.

justed to the lowest level on the gain control of the noise generator. Group IV (GG/R-GN) was given five trials per day for two days with the (GG) condition followed by five trials per day for six days with the (R-GN) condition. Groups V (--/RG) and VI $(--/ \mathbf{R}-\mathrm{GN})$ received no pre-trial experience. Group $V$ had five trials per day for six days with the (RG) condition and Group VI has the same number of trials with the (R-GN) condition.

The dependent variable for all groups was the number of responses to the arm with the green light.

\section{Results}

The data were analyzed by an analysis of variance and the groups differed significantly $(p<.05)$. A Duncan's New Multiple Range Test (Edwards, 1960) was applied to the data and the comparisons are given in Table 1.

A correlated t-test was applied to the number of right and left responses and tested against chance. No significant difference was obtained $(.10>p>.05)$.

\section{Discussion}

As predicted, the animals preferred the light plus noise to light alone (see Table 1). It was assumed that the intermodal condition was more complex than light alone. The pre-trial conditions did not seem to affect the results in any way. There was no side preference or color preference of the animals. It seems that the animals were unable to discriminate between red and green light and the only basis for discrimination between the two arms was the auditory stimulus.

\section{Conclusions}

The results of the present experiment indicate that white noise plus light are preferred to light alone and a $\mathrm{T}$-maze situation. These results are interpreted as supporting a portion of the Dember-Earl (1957) theory. Also, the results indicate that white noise can act as a motivational antecedent for choice behavior. The superior performance of the animals receiving white noise over the animals receiving light alone supports the predictions.

\section{References}

Butler, R. A. The differential effect of visual and auditory incentives on the performance of monkeys. Amer. J. Psychol, 1958 , 71, 591-593.

Dember, W. N. The psychology of perception. New York: Henry Holt and Co., Inc. 1960.

Dember, W, N., \& Earl, R. W. Analysis of exploratory, manipulatory, and curiosity behavior. Psychol. Rev., 1957, 64, 91-96.

Edwards, A. L. Experimental design in psychological research. New York: Holt, Rinehart and Winston, 1960.

Levin, H., \& Forgays, D. G. Sensory change as immediate and and delayed reinforcement for maze learning. J. comp. physiol. Psychol., 1960, 53, 195-196.

Sackett, G. P. The maturation and development of learning motivated by light change. Unpublished doctoral dissertation, Claremont Graduate School, 1963.

Symons, J. R. The effect of various hetermodal stimuli on visual sensitivity. Quart. J. exp. Psychol., 1963, 15, 243-251. 